\title{
Predictors of hospital mortality and mechanical ventilation in patients with cervical spinal cord injury
}

Andrew R. Claxton BSc MB CHB FRCA, *

David T. Wong MD FRCPC, *

Frances Chung MD FRCPC, *

Michael G. Fehlings MD PhD FRCsC ${ }^{\dagger}$

\begin{abstract}
Purpose: The objective of this study was to identify predictors of death and mechanical ventilation in patients with traumatic cervical spinal cond injury.

Methods: From 1981 to 1994, 72 patients with traumatic cervical spinal cord injury resulting in neurological deficits were identified in this retrospective study. For each patient, neurological and associated injuries, physiological variables, complications, hospital mortality and the need for mechanical ventilation were recorded. Univariate and multivariate logistic regression analyses were done to identify predictors of mortality and the need for mechanical ventilation.

Results: Fifteen patients (21\%) died in The fi/st three months after injury. Univariate analyses identified age, heart disease, neurological level at $C_{4}$ and above, GCS $\leq 13$, forced vital capacity and cough, to be associated with mortality. Multivariate logistic regression identified age $(P=0.01)$, neurological level $(P=0.03)$ and GCS $(P=0.05)$ as independent predictors of mortality. In 41 patients $(57 \%)$, the lungs were mechanically ventilated. Univariate analyses identified The following predictors of the need for mechanical ventilation: neurological level at $C_{5}$ and above, complete cord lesions, copious sputum, pneumonia and lung collapse. Multivariate logistic regression identified copious sputum $(P=0.01)$ and pneumonia $(P=0.01)$ as independent predictors of the need for mechanical ventilation.

Conclusion: Age, neurological level and GCS are independent predictors of mortality in patients with traumatic cervical spinal cord injury. Copious sputum and pneumonia are independent predictors of the need for mechanical ventilation.
\end{abstract}

Objectif : Le but de cette étude était d'identifier des éléments pronostiques de décès ou de ventilation mécanique prolongée chez des patients souffrant de traumatisme de la moëlle cervicale.

Méthodes : Dans cette étude rétrospective s'étendant de 198I à 1994, on a identifié 72 patients souffrant de traumatisme de la moëlle cervicale entrainant des déficits neurologiques. Pour chaque patient, on a compilé les blessures neurologiques et autres, les variables physiologiques, les complications, la mortalité à l'hôpital et le besoin de ventilation mécanique. On a utilisé des analyses de régression logistique à variables unique ou multiples pour identifier les éléments pronostiques de décès ou de la nécessité de ventilation mécanique prolongée.

Résultats : Quinze patients ( $21 \%$ ) sont décédés durant les trois premiers mois après le traumatisme. Selon ces analyses à variable unique, la mortalité était en relation avec l'âge, la maladie cardiaque, le niveau de lésion neurologique à $\mathrm{C} 4$ ou plus haut, le score de Glasgow $\leq 13$, la capacité vitale et la capacité de tousser. La régression logistique à variables multiples identifie comme éléments indépendants pronostiques de mortalité, l'âge $(P=0,01)$, le niveau de lésion neurologique $(P=0,03)$ et le score de Glasgow $(P=0,05)$. Pour 41 patients $(57 \%)$, on a utilisé la ventilation mécanique. Les analyses à variable unique ont identifié comme éléments pronostiques de ventilation mécanique : un niveau de lésion neurologique à $\mathrm{C} 5$ et plus haut, une section complète de la moëlle, des sécrétions abondantes, une pneumonie et un collapsus pulmonaire. La régression logistique à variables multiples identifie les sécrétions abondantes $(P<0,01)$ et la pneumonie $(P=0,01)$ comme éléments indépendants pronostiques de la nécessité d'une ventilation mécanique.

Conclusion : Chez les patients présentant une lésion traumatique de la moëlle cervicale, l'âge, le niveau de la lésion et le score de Glasgow sont des éléments pronostiques indépendants quant au décès, alors que des sécrétions bronchiques abondantes et des pneumonies prédisent le besoin de ventilation mécanique.

From The Department of Anaesthesia, ${ }^{*}$ The Division of Neurosurgery and Spinal Program, ${ }^{\dagger}$ The Toronto Hospital, Western Division, University of Toronto, 399 Bathurst Street, Toronto, Ontario, Canada-M5T 2S8.

Address correspondence to: David T. Wong MD; Phone: 416-603-5118; Fax: 416-603-6494; E-mail: dwong@torhosp.toronto.on.ca

Presented in part at The Society of Critical Care Medicine Scientific Symposium, New Orleans, February 1996. Accepted for publication Nopember 23, 1997. 
I $\mathrm{N}$ the United States, 10,000 people are rendered tetraplegic each year as a result of cervical spinal cord injuries. Five thousand of these 10,000 patients die; 4,000 die before and 1,000 die after reaching hospital.'

Patients with cervical spinal cord injuries have respiratory dysfunction, which predisposes them to respiratory complications and respiratory failure. ${ }^{2,3}$ Cardiorespiratory complications are a major cause of death in the early hospital period. ${ }^{46}$ The majority of studies concerning mortality have considered mortality over several years and have used univariate analyses only. ${ }^{7-10} \mathrm{~A}$ single study identified age, initial level of consciousness and the need for respiratory support as independent predictors of death occurring within three months of injury. ${ }^{11}$ Daverat's study included paraplegic and tetraplegic patients but did not consider other factors such as pre-cxisting disease, ${ }^{5}$ physiological or clinical changes which may be useful predictors of early hospital mortality in the initial stages of management.

We are unaware of any studies which has attempted to identify factors which predispose patients with cervical spinal cord injury to the need for mechanical ventilation. Kraus ${ }^{1}$ stated that there is a need to identify why patients who resemble each other with respect to neurological impairment have different rates of complications. The objective of this study was to identify predictors of death and the need for mechanical ventilation in the first three months of hospital management in patients with traumatic cervical spinal cord injury. This information may be useful in prognostication, in clinical decision making with respect to the need for an intensive care setting and transferal to spinal tertiary referral centres.

\section{Methods}

After approval of the Hospital's Committee for Research on Human Subjects, this retrospective study was undertaken at The Toronto Hospital, Western Division; a regional and national referral centre for the acute management of spinal cord injuries. From 1981 to 1994 , patients with cervical spinal cord injuries were identified by ICD-9 codes: ${ }^{12} 952-00$ to $952-09$ (cervical spinal cord injury without evidence of spinal bone injury) and 806-00 to 806-09 (cervical spinal cord injury with fracture of vertebral column). Patients with neurological deficits defined by the American Spinal Injury Association (ASIA) impairment scale ${ }^{13}$ of any grade other than $\mathrm{E}$ (normal) were enrolled in the study.

From review of hospital charts, at the time of hospital admission, the following data were collected: age, body mass index, smoking history, history of pre-existing cardiac (coronary artery disease, myocardial infarction, con- gestive heart failure, arrhythmia), respiratory (asthma, chronic obstructive pulmonary disease, restrictive lung disease) and psychiatric disease, mechanism of injury, neurological lesion, the presence of associated injuries to head, chest and abdomen, and the Glasgow coma scale (GCS). The American Spinal Injury Association (ASIA) impairment scale ${ }^{13}$ was used to define the neurological level which was determined as the most caudal segment of the spinal cord with normal motor and sensory function on both sides of the body (Table I). Complete spinal cord lesion consisted of patients with ASIA class A while incomplete lesion cncompassed patients with ASIA classes B, C or D. Class $E$ indicated normal motor and sensory function.

During the hospital stay, the following respiratory variables were recorded: forced vital capacity (FVC), ability to cough and the quantity of sputum. The ability to cough (absent, weak or strong) and the quantity of sputum (copious, moderate or light) were recorded by ICU nurses on the ICU daily flowsheets. The grading scheme for cough and sputum production were printed on the ICU flowsheets to facilitate uniformity in recording. The study data on cough and sputum were obtained from review of each patient's ICU flowsheet. The worst values in each week of hospital stay were recorded.

Complications recorded included (a) Respiratory: pneumonia (temperature $>38.5^{\circ} \mathrm{C}$, white blood count $>12.0 \times 10^{9} \cdot \mathrm{L}^{-1}$, positive sputum culture and new infiltrate on chest radiograph), major lobar collapse (based on clinical findings confirmed by radiological evidence) and pulmonary embolus (diagnosed by ventilation perfusion scan or pulmonary angiogram); (b) Cardiovascular: pulmonary oedema (both clinical and radiological findings), cardiac arrest, myocardial infarction (two of chest pain, ECG changes or elevated $\mathrm{CK}-\mathrm{MB}$ ) and multi-organ system failure (ztwo organ system failure). ${ }^{14}$

\section{TABLE I ASIA impairment scale ${ }^{33}$}

\begin{tabular}{|c|c|}
\hline Class & Impairment \\
\hline A & $\begin{array}{l}\text { Complete: No motor or sensory function is preserved in } \\
\text { the sacral segments } S_{4}-S_{5}\end{array}$ \\
\hline B & $\begin{array}{l}\text { Incomplete: Sensory but not motor function is preserved } \\
\text { below the neurological level and extends through the sacral } \\
\text { segments } S_{4}-S_{5}\end{array}$ \\
\hline C & $\begin{array}{l}\text { Incomplete: Motor function is preserved below the } \\
\text { neurological level, and the majority of key muscles below } \\
\text { the neurological level have a muscle grade }<3\end{array}$ \\
\hline $\mathbf{D}$ & $\begin{array}{l}\text { Incomplete: Motor function is preserved below the } \\
\text { neurological level, and the majority of key muscles below } \\
\text { the neurological level have a muscle grade of } \geq 3\end{array}$ \\
\hline $\mathbf{E}$ & Normal: Motor and sensory function is normal \\
\hline
\end{tabular}


The duration of stay in the ICU and in hospital were recorded. The outcome variables were: (a) early hospital mortality, defined as death in hospital within three months of hospital admission, and (b) the need for mechanical ventilation, defined as mechanical ventilation at any time during hospital stay except those ventilated for less than $24 \mathrm{hr}$ after surgical procedures. The decision to intubate the trachea and ventilate the lungs was made on clinical grounds by an attending anaesthetist in the neurosurgical ICU.

Data, expressed as mean $\pm S D$ ), were entered into a computerised data base (Microsoft Access, version 2.0) and analysed using the statistical program SAS, version 6.10 (SAS Institute Inc., SAS Campus Drive, NC 27513, USA). Univariate analysis was performed initially. Parametric data were analysed using the unpaircd $t$ test and categorical data using $\chi^{2}$ analysis or Fisher's Exact test. Multivariate logistic regression analyses were performed to determine independent predictors of death and the need for mechanical ventilation. ${ }^{15}$ Factors were entered into separate multiple logistic models based upon the results of univariate analyses (factors with $P<0.10$ ). $P<0.05$ was considered statistically significant.

\section{Results}

From the ICD-9 coding for cervical spine injuries, 210 charts were extracted. Ninety patients with cervical spinal cord lesions with neurological deficits were identified. Eighteen patients with incomplete data were eliminated resulting in 72 patients in this study. There were 10 women and 62 men. The age of patients ranged from $15-83 \mathrm{yr}, 48.3 \pm 19.4 \mathrm{yr}$.

All injuries were the result of blunt trauma and the mechanisms of injury are listed in Table II. Fifty-six (77\%) of patients were admitted within $24 \mathrm{hr}$ of injury. The level and completeness of cervical spinal cord injuries are shown in Figure 1; 39 were complete and 33 were incomplete lesions of the spinal cord. The majority of patients had isolated cervical spinal injuries. Eight patients had associated head injuries, three had associated chest injuries and two had abdominal injuries requiring laparotomy. All patients were managed in a neurosurgical ICU. The mean \pm SD duration of hospital stay was $46.2 \pm 47$ days. No patients who survived to be discharged from hospital continued to require mechanical ventilation.

Fifteen patients $(21 \%)$ died. Thirteen patients died in the ICU. Deaths occurring outside the ICU included one patient who sustained a cardio-respiratory arrest and a second who refused ventilation for the third time. The primary cause of death was neurological in two, cardiac in two, respiratory in nine and multiple organ system failure in two. The two patients who died primarily from neurological causes died of severe hypoxic encephalopathy as a result of cardiopulmonary arrest occurring outside hospital.

The results of the univariate analysis of categoric variables associated with death are shown in Table III. The mean age $\pm S D$ of survivors was $41 \pm 18.6 \mathrm{yr}$ and of non-survivors $69 \pm 11.6 \mathrm{yr}(P=0.001)$. Two of 36

TABLE II Mechanism of injury

\begin{tabular}{ll}
\hline Mechanism & Number (\%) \\
\hline Falls/jumps & $32(44 \%)$ \\
Motor vehicle accidents & $26(36 \%)$ \\
Sports injuries & $10(14 \%)$ \\
Hit by an object & $4(6 \%)$ \\
Total & $72(100 \%)$ \\
\hline
\end{tabular}

TABLE III Univariate analysis of variables associared with death

\begin{tabular}{lcccc}
\hline Variable & $\begin{array}{c}\text { No. with } \\
\text { variable }\end{array}$ & $\begin{array}{c}\text { Death rate with } \\
\text { variable }\end{array}$ & P value \\
\hline & \multicolumn{4}{c}{ Present } \\
Heart disease & 7 & $57 \%$ & $17 \%$ & 0.031 \\
Neuro level $\mathrm{C}_{4}$ and above & 28 & $50 \%$ & $2 \%$ & 0.001 \\
GCS $^{\dagger}<=13$ & 8 & $63 \%$ & $16 \%$ & 0.001 \\
Absent cough (week 1) & 8 & $87 \%$ & $7 \%$ & 0.001 \\
\hline
\end{tabular}

* Comparing the death rates in patients with presence or absence of variable.

${ }^{\dagger}$ Neuro level $\mathrm{C}_{4}$ and above refers to higher cervical anatomical lesions. i.e., $\mathrm{C}_{2}$ to $\mathrm{C}_{4}$

₹ Glasgow Coma Scale.

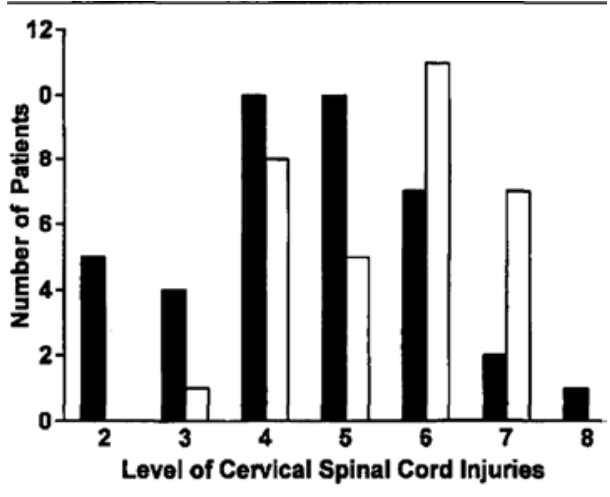

FIGURE 1 Graph showing the number of patients with complete or incomplete spinal cord lesions at different levels of cervical spinal cord injuries.

- complete $\square$ incomplete 
patients $<40 \mathrm{yr}$ died compared with 13 of 36 patients $>40 \mathrm{yr}(P=0.004)$. Forced vital capacity in the first week for survivors was $2.11 \pm 1.99 \mathrm{~L}$ and for non survivors was $0.62 \pm 0.57 \mathrm{~L},(P=0.02)$. Pre-existing chest disease, associated injuries to the chest or abdomen and copious sputum were not associated with hospital mortality. Age $>40$ yr, forced vital capacity in the first week, heart disease, neurological level, GCS, cough, pneumonia and the need for mechanical ventilation were entered into the multiple logistic model. ${ }^{15}$ The neurological level for this analysis was stratified into four groups: $C_{2-3}, C_{4}, C_{5}, C_{6}, C_{7}-T_{1}$. Age $(P=0.013$, Odds ratio $(\mathrm{OR})=1.22,95 \%$ confidence interval $(C I)=1.09,1.44)$, neurological level at $\mathrm{C}_{4}$ or above $(P=0.025, \mathrm{OR}=4.94, \mathrm{CI}=2.0,12.6)$ and $\mathrm{GCS}<=13(P=0.05, \mathrm{OR}=5.0, \mathrm{CI}=1.6,15.1)$ were identified as independent predictors of death.

Forty-one $(57 \%)$ patients received mechanical ventilation. In $29(70 \%)$ ventilation was initiated for respiratory failure: $26(90 \%)$ of these within three days of the injury, in four patients mechanical ventilation followed cardiorespiratory arrest and eight patients required ventilation for $>24 \mathrm{hr}$ after surgical procedures. The duration of ventilation was $11 \pm \mathbf{3 1}$ days.

From univariate analysis, injury to the cervical spine at $\mathrm{C}_{5}$ level and above, complete lesions, copious sputum, pneumonia and major lobar collapse were associated with the need for mechanical ventilation (Table IV). Smoking, heart and chest disease, associated injuries of the head or chest, forced vital capacity or ability to cough were not associated with the need for ventilation. Neurologic level, complete lesion, copious sputum, pneumonia and major lobar collapse were entered into the multiple logistic model. The level of the neurologic lesion for this analysis was stratified into two groups: lesions at $C_{5}$ and above (i.e., $C_{2}$ to $C_{5}$ )

TABLE IV Univariate analysis of variables associated with ventilation

\begin{tabular}{|c|c|c|c|c|}
\hline \multirow[b]{2}{*}{ Variable } & \multirow{2}{*}{$\begin{array}{l}\text { No. with } \\
\text { variable }\end{array}$} & \multicolumn{2}{|c|}{$\begin{array}{l}\text { Ventilation } \\
\text { witb variable }\end{array}$} & \multirow[b]{2}{*}{ P palate } \\
\hline & & Present & Absent & \\
\hline Neuro level C5 and above ${ }^{\dagger}$ & 43 & $69 \%$ & $39 \%$ & 0.002 \\
\hline Complere lesion of $\mathrm{CSC}^{\mp}$ & 39 & $72 \%$ & $13 \%$ & 0.01 \\
\hline Copious sputum (week 1) & 23 & $96 \%$ & $44 \%$ & 0.001 \\
\hline Pneumonia & $\mathbf{3 3}$ & $91 \%$ & $26 \%$ & 0.001 \\
\hline Major lobe collapse & 19 & $95 \%$ & $43 \%$ & 0.0001 \\
\hline
\end{tabular}

* Comparing the incidence of ventilation in patients with presence or abscnce of variable.

t Neurological level $C_{5}$ and above refers to higher anatomical lesions. i.e., $C_{3}$ to $C_{5}$

t Cervical spinal cord. and lesions below $\mathrm{C}_{5}$. Copious sputum in the first week $(P=0.01, \mathrm{OR}=7.13, \mathrm{CI}=1.1,160)$ and pneumonia $(P=0.01$, OR $=11.1, \mathrm{CI}=2.0,104.5)$ were found to be independent predictors of the need for ventilation. Neurological level was associated with the need for mechanical ventilation with borderline statistical significance $(P=0.08, \mathrm{OR}=4.44, \mathrm{CI}=0.9,27.1)$.

\section{Discussion}

Our results show that increased age, level of neurological lesion and GCS on arrival are independent predictors of early hospital death after traumatic cervical spinal cord injury. Age has consistently been a factor associated with a poor outcome in patients with spinal cord injuries. ${ }^{7,8}$ We demonstrated that age $>40 \mathrm{yr}$ was associated with an increased incidence of mortality. This is in agrecment with Bellamy ${ }^{5}$ who suggested patients sustaining cervical spinal cord injuries $>40 \mathrm{yr}$ had higher mortality and Wicks ${ }^{16}$ who showed mortality of patients $>\mathbf{5 0} \mathrm{yr}$ was greater in tetraplegic patients requiring long term ventilation. Daverat showed age to be an independent factor predicting death when considering outcome in series including all levels of spinal cord injury." Elderly patients generally have a poor outcome after trauma; age $>55 \mathrm{yr}$ is an independent predictor of death after multiple trauma. ${ }^{17}$ Age and co-morbidity can both contribute to increased mortality in spinal cord injury.

We found that neurological level of injury of $\mathrm{C}_{4}$ and above was an independent predictor of mortality. Studies have identified the level of the cord lesion to be of importance in determining outcome following spinal cord injuries. ${ }^{7,8}$ Daverat ${ }^{11}$ used multivariate logistic regression and did not identify neurological level to be an independent predictor of mortality. Daverat attributed this to the bias introduced by the use of univariate analysis only in other studies. Daverat's series differed from ours; they included spinal cord lesions resulting in both paraplegia and tetraplegia. We included only patients with cervical spinal cord injuries with neurological deficits. Furthermore, they used a different scoring system to evaluate neurological level and the highest mortality in their series was with lesions at $\mathrm{C}_{6}-\mathrm{T}_{1}$. This may reflect the incidence of thoracic injuries which was $25 \%$ in their series. In our series, three of 72 had associated thoracic injuries.

The third independent predictor of mortality was the GCS on hospital admission. This is in agreement with Daverat ${ }^{11}$ who showed an initial conscious level was an independent predictor of mortality. The initial GCS in patients with cervical spinal cord injuries may reflect either associated head injury or hypoxic brain damage associated with severe respiratory insufficien- 
cy prior to resuscitation. It is also recognised that head injuries are associated with a spectrum of respiratory abnormalities including neurogenic pulmonary oedema, aspiration pneumonia, ventilation: perfusion mismatch and abnormal ventilatory patterns, producing pulmonary dysfunction ${ }^{18}$ which may contribute to early death.

Our results showed that copious sputum in the first week and pneumonia were independent predictors of need for mechanical ventilation. Studies specifically addressing factors associated with the need for mechanical ventilation in patients with cervical spinal cord injuries have not been reported. The studies which are available have described the incidence of respiratory complications, the need for tracheostomy and related these to patient factors: age, pre-existing disease and associated injuries ${ }^{5}$ and nature of the lesion being complete or incomplete. ${ }^{6}$

Copious sputum was an independent predictor of the need for ventilation. It was recognised that close attention to the prevention, recognition and treatment of secretion retention may reduce the need for mechanical ventilation after the onset of traumatic tetraplegia. ${ }^{19}$ Pneumonia was also independently associated with the need for mechanical ventilation, although the cause-effect relationship cannot be determined. It does suggest, however, that the retention of secretions may cause pneumonia leading to the need for mechanical ventilation.

In our series, level of injury at $C_{5}$ and above was identified by univariate analysis to be associated with the need for mechanical ventilation. However, with multiple logistic regression analysis, the level of injury was associated with need for ventilation with borderline significance $(P=0.08)$. From a physiological standpoint, it is logical that a higher neurological level should be associated with more respiratory compromise and, therefore, the need for mechanical ventilation. It is quite possible that we may fail to show this association due to a type II statistical error resulting from small sample size. There may also be an alternative explanation. High lesions of the cervical spinal cord involving the phrenic nerve nuclei will impair diaphragmatic function. All quadriplegics, however, have lost intercostal muscle function and have forced vital capacities around $33 \%$ of normal resulting in considerable impairment of ventilatory function. ${ }^{2}$ Therefore, patients with level of injury below $\mathrm{C}_{5}$ are susceptible to respiratory dysfunction and failure.

There are several limitations to this srudy. First, it was retrospective. Information which allows us to determine the presence or absence of a condition may be missing or recorded inaccurately in the chart. Second, although this was an extensive review over $13 \mathrm{yr}$, the sample size is still small. In univariate and multivariate analyses, to determine predictors of death and ventilation, a negative association may have resulted from the low incidence of occurrence of the predictive variable or the outcome ( $B$ error). For example, in clinical experience, low FVC or inability to cough are thought to be strongly associated with need for mechanical ventilation. However, neither factor was found to be an independent predictor of need for mechanical ventilation in logistic regression analyses. Third, this study reflected the experience at a tertiary referral spinal trauma centre. The predictors found may not be generalisable to patients with spinal injuries managed at community hospitals. Fourth, the predictors derived were from cervical spinal cord injury patients with neurological deficits who were all treated in the ICU. Therefore, they should not be generalised to a general cervical spinal injury population. Fifth, the predictors derived have not been validated prospectively in an independent population. In future, our goal is to validate these predictors in prospectively collected data using receiver operating characteristic curves and goodness of fit tests. Lastly, pneumonia is very difficult to diagnose in the ICU. We did not attempt to use bronchoscopic derived microbiological data to diagnose pneumonia in this retrospective review.

In conclusion, age, level of cervical spinal cord injury and GCS on arrival are independent predictors of early hospital death in patients with traumatic cervical spinal cord injuries. Copious sputum in the first week after injury and pneumonia are independent predictors of the need for mechanical ventilation. We acknowledge that these conclusions need to be interpreted with caution due to the limitations cited above. Findings here may be used to generate hypotheses which can be further tested in a prospective study.

\section{Acknowledgment}

This study was supported, in part, by the Department of Anaesthesia, The Toronto Hospital, Western Division, The University of Toronto.

The authors wish to thank Sonia Kearns RN FV for her assistance in data collection and Santhira Vairavanthan $\mathrm{MD}$ for her help with data entry.

\section{References}

1 Kraus JF. Epidemiologic features of head and spinal cord injury. Adv Neurol 1978; 19: 261-79.

2 Ledsome JR, Sharp JM. Pulmonary function in acute cervical cord injury. Am Rev Respir Dis 1981; 124: 41-4.

3 Ohry $A$, Mollo $M$, Rozin $R$. Alterations of pulmonary function in spinal cord injured patients. Paraplegia 1975; 13: 101-8. 
4 Silver JR, Gibbon NOK. Prognosis in tetraplegia. BMJ 1968; 4: 79-83.

5 Bellamy R, Pitts FW, Stauffer ES. Respiratory complications in traumatic quadriplegia. J Neurosurg $1973 ; 39$ : $596-600$.

6 Kraus FJ, Frauti CE, Borbani NO, Riggins RS. Survival with acute spinal-cord injury. Journal of Chronic Disease 1979; 32: 269-83.

7 Mesard L, Carmody A, Mannarino E, Ruge D. Survival after spinal cord trauma. $\mathrm{A}$ life table analysis. Arch Neurol 1978; 35: 78-83.

8 DeVivo $M$ J, Kartus $P L$, Stover $S L$, Rutt RD, Fine $P R$. Seven-year survival following spinal cord injury. Arch Neurol 1987; 44: 872-5.

9 DeVivo MJ, Stover SL, Black KJ. Prognostic factors for 12-year survival after spinal cord injury. Arch Phys Med Rehabil 1992; 73: 156-62.

10 DeVivo MJ, Ivie CS III. Life expectancy of ventilatordependent persons with spinal cord injuries. Chest 1995; 108: 226-32.

11 Daverat $P$, Gagnon $M$, Dartigues JF, Mazaux JM, Barat $M$. Initial factors predicting survival in patients with a spinal cord injury. J Neurol Neurosurg Psychiatry 1989; 52: 403-6.

12 The International Classification of Disease, 9th revision, clinical modification: ICD-9-CM. Washington: U.S. Dept of Health and Human Services, 1986: 742, 743,832 .

13 International standards for neurological and functional classification of spinal cord injury. American Spinal Injury Association, Chicago, Illinois: Ditunno JF, 1992.

14 Knaws WA, Draper EA, Wagner DP, Zimmerman JE. Prognosis of acute organ-system failure. Ann Surg 1985; 202: 685-93.

15 Hosmer DW, Lemeshow S. Applied Logistic Regression. New York: John Wiley and Sons, 1989: 25-37.

16 Wicks $A B$, Menter $R R$. Long-term outlook in quadriplegic patients with initial ventilator dependency. Chest 1986; 90: 406-10.

17 Boyd CR, Tolson MA, Copes WS. Evaluating trauma Care the TRISS method. J Trauma 1987; $27: 370-8$.

18 Demling $R$, Reissen $R$. Pulmonary dysfunction after cerebral Injury. Crit Care Med 1990; 18: 768-74.

19 McMichan JC, Michel L, Westbrook PR. Pulmonary dysfunction following traumatic quadriplegia. JAMA 1980; 243: 528-31. 